\title{
Сравнение возможностей углеродных сорбционно-активных материалов для экспрессного концентрирования летучих органических соединений из потока анализируемого воздуха
}

\author{
(C) 2021 Родинков О.В., Постнов В.Н., Спиваковский В., Бугайченко А.С. \\ Санкт-Петербургский государственный университет, Институт химии, Санкт-Петербург
}

Поступила в редакцию 10.01.2020 г.

DOI: $10.17308 /$ sorpchrom.2021.21/3464

Углеродные сорбенты широко используются для динамического сорбционного концентрирования определяемых веществ в анализе воздуха. Однако углеродные и особенно наноуглеродные сорбционно-активные материалы имеют один существенный недостаток. Слишком мелкие частицы этих материалов часто препятствуют их непосредственному применению при анализе воздуха из-за низкой проницаемости сорбционного слоя. Решить проблему низкой проницаемости микродисперсных сорбционно-активных материалов можно с помощью композиционных поверхностно-слойных сорбентов, в которых эти материалы находятся на поверхности относительно крупнодисперсного носителя.

Основная цель работы - оценка возможностей поверхностно-слойных сорбентов на основе различных углеродных материалов для экспрессного концентрирования высокотоксичных летучих органических соединений (средних спиртов и фенолов). Синтезированы и исследованы поверхностно-слойные сорбенты на основе коммерчески доступных углеродных нанотрубок (Bayer, Dealton, Таунит-МД) и нанотрубок, синтезированных собственноручно с использованием кобальтового катализатора. Перечисленные углеродные сорбенты наносили на кремнеземные носители на основе аэросилогеля. Выбор этих носителей обусловлен их высокой термической устойчивостью и возможностью нанесения на их поверхность слоев пироуглерода и углеродных нанотрубок. Кроме того, эти носители позволяют создавать композиты с самыми различными сорбционно-активными углеродными материалами.

Наибольшая эффективность установлена для поверхностно-слойных сорбентов на основе углеродных нанотрубок, полученных с использованием кобальтового катализатора. Эффективность этих сорбентов по величине ВЭТТ существенно выше, чем у сорбентов на основе графитированной термической сажи (Карбопаки) с сопоставимой удельной поверхностью. Особенно сильно достоинства поверхностно-слойных сорбентов начинают проявляться при высоких скоростях анализируемого воздуха. Повышенная гидрофильность некоторых синтезированных композитов затрудняет их применение при анализе влажного воздуха с ориентацией на последующую термодесорбцию аналитов. Хотя при этом остается возможность десорбции с помощью подходящего органического растворителя с последующим определением аналитов методом ВЭЖХ.

Общеизвестны трудности термодесорбции высококипящих органических соединений с поверхности углеродных адсорбентов. Для решения этой проблемы синтезированы поверхностно-слойные сорбенты со слоем пироуглерода на поверхности макропористого носителя порохром-3 для газовой хроматографии с небольшой удельной поверхностью. Предложенные сорбенты дают возможность проводить сорбционное концентрирование фенола и изомерных крезолов за 5 минут с коэффициентом концентрирования $2 \cdot 10^{3}$ с последующим газохроматографическим определением аналитов (пламенноионизацонный детектор) на уровне нескольких мкг/м³. Это создает необходимые предпосылки для экспрессного определения фенола и изомерных крезолов на уровне предельно допустимых концентраций воздуха жилых помещений и атмосферного воздух населенных мест.

Ключевые слова: сорбенты, поверхностно-слойные, концентрирование, воздух, анализ, углеродные нанотрубки, аэросилогель, фенолы, спирты. 


\section{Введение}

В настоящее время определение большинства загрязнителей атмосферного воздуха и воздуха жилых помещений нуждается в концентрировании аналитов [1]. Даже при использовании наиболее чувствительных детекторов в газовой и жидкостной хроматографии для определения на уровне ПДК, например, фенолов коэффициент концентрирования должен быть $\left(10^{3}-10^{4}\right)$ [2]. К наиболее эффективным методам концентрирования относится сорбция, которую в последние годы называют твердофазной экстракцией (ТФЭ) $[3,4]$. Возможности ТФЭ в её наиболее распространенном варианте твердофазной микроэкстракции ограничены небольшой массой сорбирующей фазы (0.2-2 мг), и, соответственно, относительно небольшими количествами сорбируемых аналитов, недостаточными для достижения низких пределов обнаружения $[5,6]$.

В этом отношении предпочтительнее динамическая ТФЭ, основанная на пропускании анализируемого газа через колонку с сорбентом, с последующей термодесорбцией или десорбцией органическим растворителем аналитов и их хроматографическим определением [2,3,7]. К настоящему времени для реализации ТФЭ предложены самые различные сорбенты [8-11], включая углеродные и наноуглеродные [10] с различной удельной поверхностью и гидрофобностью. Однако углеродные и особенно наноуглеродные сорбционно-активные материалы имеют один существенный недостаток. Слишком мелкие частицы этих материалов довольно часто препятствуют их непосредственному применению при анализе воздуха из-за низкой проницаемости сорбционного слоя.

Решить проблему низкой проницаемости микродисперсных сорбционно-активных материалов удалось с помощью композиционных поверхностно-слойных сорбентов, в которых эти материалы находятся в порах относительно крупнодисперсного носителя [12]. В частности, угольно-фторопластовые сорбенты позволили без потери эффективности извлечения аналитов в несколько раз повысить допустимую скорость пропускания анализируемого воздуха через сорбционные колонки и тем самым многократно снизить продолжительность стадии сорбционного концентрирования летучих органических соединений [2, 13-15]. Однако в этих сорбентах микрочастицы углеродных материалов удерживаются на поверхности фторопластового носителя за счет относительно слабой физической адгезии и осыпаются при встряхивании или пересыпании сорбента.

Цель настоящей работы - оценка возможностей сорбентов на основе графитированных термических саж, пироуглерода и многослойных углеродных нанотрубок, нанесенных на кремнеземные сорбенты-носители, применительно к экспрессному концентрированию из потока воздуха высокотоксичных летучих органических соединений: средних спиртов и фенолов. В качестве тестовых веществ выбраны бутнаол-1 и фенол, которые имеют очень низкие ПДК $\left(0.01 \mathrm{мг} / \mathrm{M}^{3}\right)$ и для определения которых на уровне ПДК требуется высокоэффективное концентрирование (коэффициентом концентрирования должен быть не менее $2 \cdot 10^{3}$ ).

Выбор кремнеземного носителя представляется оправданным благодаря его высокой термической устойчивости, возможности нанесения на поверхность слоев пироуглерода и углеродных нанотрубок, а также возможностью создания на его основе композитов, содержащих различные сорбционно-активные углеродные материалы [16-18]. Известно применение композитов на основе кремнезема и углеродных нанотрубок в качестве сорбентов в игловых концентраторах $[19,20]$, которым присущи те же недостатки, что и устройствам для твердофазной микроэкстракции. 


\section{Эксперимент}

Получение исследуемых композиционных сорбентов. Углеродные нанотрубки синтезировали на поверхности кремнеземных носителей, характеристики которых приведены в таблице 1.

Аэросилогели (АСГ) представляют собой синтетические кремнеземы $\left(\mathrm{SiO}_{2}\right)$ с жесткой пористой структурой и приблизительно однородными по размерам порами. Аэросилогель- 800 был получен по стандартной методике [18] путем приготовления геля аэросила с последующей гидротермальной обработкой при $800^{\circ} \mathrm{C}$ в течение 6 часов. Аэросилогель-900 готовили по аналогичной методике, однако, гидротермальную обработку проводили при $900^{\circ} \mathrm{C}$. Более жесткие условия гидротермальной обработки, как видно из данных таблицы 1, привели к уменьшению величины удельной поверхности и к увеличению размера пор. В обоих синтезах использовался аэросил марки А-200 фирмы Degussa.

Кобальт, который служил катализатором для получения углеродных нанотрубок, наносили на поверхность кремнезема методом ионного обмена, используя аммиачные комплексы кобальта. Синтез углеродных нанотрубок на образцах АСГ-900, КСК-2 проводили в среде водорода в режиме кипящего слоя при $600^{\circ} \mathrm{C}$ по методике [21], а на образце АСГ-800 при $800^{\circ} \mathrm{C}$. Изменение температуры синтеза позволяет варьировать содержание углерода, что должно отражаться на сорбционных свойствах синтезируемых поверхностно-слойных угольно-кремнеземных сорбентов.

Композиционные сорбенты, содержащие кремнеземный носитель и углерод- ные нанотрубки в равных весовых пропорциях получали, используя гель аэросила А-380, который смешивали с навесками соответствующих коммерческих доступных нанотрубок: Таунит-МД (производитель ООО «НаноТехЦентр»), DEALTOM (производитель НПП «Центр нанотехнологий») и BayTUBES C-150P (производитель фирма «Вауег»).

Синтез поверхностнослойного сорбента на основе порохрома-3, макропористого носителя для газовой хроматографии с содержанием кремнезема 96-98\%, проводили по методике [22]. Пары пропаргилового спирта пропускали через слой порохрома 3 в режиме кипящего слоя при $800^{\circ} \mathrm{C}$ в течение двух часов. Газом-носителем служил азот.

Синтезированные в настоящей работе сорбенты по эффективности сравнивали с широко используемыми сорбентами на основе графитированной термической сажи - Карбопаками C, В и X Карбографом-1 (все сорбенты производства Sigma-Aldrich, USA).

Оценка порометрических показателей сорбентов. Определение удельной поверхности и распределения пор по размерам проводили по стандартной методике с помощью адсорбционно-структурного метода, основанного на физической адсорбции газообразного азота при температуре 77 К [23]. Перед измерениями образцы сорбентов подвергали дегазации в вакууме при $300^{\circ} \mathrm{C}$ в течение 10 часов для удаления сорбированных газов и воды.

Получение модельных газовых смесей. Для оценки эффективности исследуемых сорбентов использовали модельные газовые смеси с постоянной концентрацией аналитов 50 мг $/ \mathrm{m}^{3}$. Эти смеси получали путем пропускания потока воздуха

Таблица1. Характеристики используемых кремнеземных носителей

Table 1. Characteristics of the used silica carriers

\begin{tabular}{|r|c|c|c|}
\hline $\begin{array}{r}\text { № } \\
\text { п/п }\end{array}$ & Кремнеземный носитель & $\begin{array}{c}\text { Удельная поверх- } \\
\text { ность, } \mathrm{m}^{2} / \Gamma\end{array}$ & $\begin{array}{c}\text { Средний размер } \\
\text { пор, нм }\end{array}$ \\
\hline 1 & Аэросилогель (АСГ)-800 & 130 & 25 \\
\hline 2 & Аэросилогель (АСГ)-900 & 70 & 80 \\
\hline 3 & Силикагель КСК-2 & 360 & 12 \\
\hline
\end{tabular}


через водные растворы с заданной концентрацией аналитов [24] с чистотой не ниже «чда». Модельные газовые смеси получали раздельно для бутанола-1 и фенола. Установлено, что в выбранном диапазоне объемных скоростей потока воздуха (100-400) см³/мин обеспечивается равновесное распределение тестовых веществ между водной и газовой фазами и постоянство их концентрации в газовой фазе. Об этом можно судить по постоянству концентрации аналитов в потоке модельных газовых смесей, получаемых при различных скоростях потоках воздуха. Значения коэффициентов распределения аналитов между водной и газовой фазой определяли по известной методике [25].

Оценка аналитических возможностей сорбентов. Перед применением сорбенты промывали ацетоном для десорбции сорбированных ранее примесей и сушили в токе газа-носителя (азота) в течении 15 минут при температуре $240^{\circ} \mathrm{C}$. Для оценки эффективности исследуемых сорбентов через колонки, заполненные навесками этих сорбентов, пропускали модельные газовые смеси аналитов с заданным расходом $\left(W_{\mathrm{G}}\right)$. Для контроля полноты сорбции отбирали порции газовой фазы на выходе из колонки и с помощью газового хроматографа определяли в них концентрации аналитов. Строили выходные кривые удерживания тестовых веществ в виде зависимостей $c / c_{0}$ от $V$, где $c$ и $c_{0}$ - концентрация тестового вещества в газовой фазе на выходе из колонки и на входе в нее соответственно; $V$ - объем модельной газовой смеси, пропущенной через колонку. Из полученных кривых для каждого аналита находили объем удерживания $\left(V_{\mathrm{R}}\right)$, за который принимали объем пропущенной через колонку газовой смеси, для которого выполняется условие $c / c_{0}=0.5$, а также рассчитывали число эквивалентных теоретических тарелок $N$, характеризующее эффективность сорбционной колонки, по предложенной для фронтального варианта хроматографии формуле [26]:

$$
N=\frac{V_{R}^{2}}{\left(V_{R}-V_{016}\right)^{2}}
$$

где $\mathrm{V}_{\mathrm{R}}$ - объем удерживания; $\mathrm{V}_{0,16}$ - такой объем пропущенной через колонку газовой фазы, для которого выполняется условие $c / c_{0}=0.16$. Высоту, эквивалентную теоретической тарелке (ВЭТТ) рассчитывали по формуле: $H=l / N$.

Оценка гидрофильности сорбентов. Для оценки гидрофильности сорбентов, которая при анализе влажных газовых сред играет отрицательную роль, определяли массу поглощенного водяного пара при пропускании через колонку с исследуемым сорбентом воздуха с относительной влажностью 99\% при комнатной температуре $22 \pm 1^{\circ} \mathrm{C}$. Эту массу относили к массе сорбента в колонке. Сорбент предварительно дегазировали при температуре $190^{\circ} \mathrm{C}$ в течении 4-5 часов до постоянной массы. Для создания потока воздуха с указанной влажностью этот поток пропускали через $1 \%$ водный раствор $\mathrm{NaCl}$.

Оборудование. Порометрические исследования сорбентов проводили на волюметрическом адсорбомере Micromeritics ASAP 2020 MP (производство «Micromeritics», США). Содержание углерода в синтезированных композиционных сорбентах определяли методом дифференциально-термического анализа на приборе SETSYS Evolution 16 (Setaram, Франция), нагревая исследуемые образцы сорбентов в атмосфере воздуха до $900^{\circ} \mathrm{C}$. Определение тестовых веществ выполняли с помощью газового хроматографа «Кристалл-5000.2» (производство «Хроматэк», Россия) снабженного пламенно-ионизационным детектором (ПИД) и капиллярной колонкой $(10 \mathrm{м} \times 0.53 \mathrm{мм} \times 2.65$ мкм) ВРX-1 (100\% диметилполисилоксан). Регулирование потока воздуха при получении модельных газовых смесей осуществляли с помощью формирователя газовых потоков 
Таблица 2. Характеристики и сорбционные свойства исследованных сорбентов. УНТ - углеродные нанотрубки; АСГ - аэросилагель; ПУ - пироуглерод

Table 2. Characteristics and sorption properties of the studied sorbents. CNT - carbon nanotubes; ASG - aerosilagel; PyC - pyrocarbon

\begin{tabular}{|c|c|c|c|c|c|c|}
\hline & \multirow[t]{2}{*}{ Сорбент } & \multirow{2}{*}{$\begin{array}{c}\text { Удельная } \\
\text { поверх- } \\
\text { ность, } \text { м² }^{2}\end{array}$} & \multirow{2}{*}{$\begin{array}{c}\text { Содержа- } \\
\text { ние угле- } \\
\text { рода, } \%\end{array}$} & \multirow{2}{*}{$\begin{array}{c}\text { Гидро- } \\
\text { филь- } \\
\text { ность, \% }\end{array}$} & \multicolumn{2}{|c|}{$\begin{array}{c}\text { Удельный объем } \\
\text { удерживания, дм } / \Gamma\end{array}$} \\
\hline & & & & & $\begin{array}{c}\text { Бутанол- } \\
1\end{array}$ & Фенол \\
\hline 1 & Карбопак C & 12 & $>98$ & 0.3 & $<1$ & 29 \\
\hline 2 & Карбопак В & 110 & $>98$ & 1.3 & 29 & 340 \\
\hline 3 & Карбопак X & 240 & $>98$ & 1.5 & 69 & 730 \\
\hline 4 & Карбограф-1 & 100 & $>98$ & 0.9 & 23 & 580 \\
\hline 5 & УНТ-АСГ - 800 & 250 & 3.4 & 5.9 & 95 & 690 \\
\hline 6 & УНТ - АСГ- 900 & 330 & 17 & 5.4 & 115 & 1340 \\
\hline 7 & УНТ-КСК-2 & 290 & 16 & 13 & 105 & 645 \\
\hline 8 & Bayer + АCГ & 201 & 49 & 15 & 32 & 680 \\
\hline 9 & Dealton $+\mathrm{AC} \Gamma$ & 140 & 48 & 13 & 60 & 735 \\
\hline 10 & Таунит-МД + АСГ & 226 & 50 & 18 & 93 & 1220 \\
\hline 11 & Порохром-3 & 2.6 & $<0.1$ & 0.8 & $<1$ & 5.9 \\
\hline 12 & Порохром-3 - ПУ & 2.8 & 1.2 & 0.26 & $<1$ & 10 \\
\hline
\end{tabular}

«Хроматэк-Кристалл ФГП». Дозирование газовых проб осуществляли с помощью автоматического обогреваемого шестипортового крана-дозатора. Для термодесобции использовали одностадийный термодесорбер ТДС-1 производства «Хроматэк», обеспечивающий проведение термодесорбции в диапазоне от 150 до $400^{\circ} \mathrm{C}$ с дискретностью $50^{\circ} \mathrm{C}$.

\section{Обсуждение результатов}

Полученные экспериментальные результаты свидетельствуют о высокой эффективности синтезированных сорбентов. Установленные характеристики этих сорбентов, включая удельные объемы удерживания тестовых веществ при комнатной температуре $22 \pm 1^{\circ} \mathrm{C}$, приведены в таблице 2.

Как видно из этой таблицы, полученные в настоящей работе композиционные сорбенты, по сорбционной емкости превосходят сорбенты на основе графитированной термической сажи (1-4) с сопоставимой удельной поверхностью. Особенно привлекателен поверхностнослойный сорбент УНТ-АСГ-900, который не только обладает максимальной сорбционной емкостью по отношению к те- стовым веществам, но и достаточно гидрофобен на фоне своего аналога (сорбент-7) и композитов (8-10). Последние, несмотря на многократно более высокое содержание углеродных нанотрубок в своем составе, уступают УНТ-АСГ-900 по сорбционной емкости и гидрофобности. Высокая гидрофильность композитов (8-10) и поверхностно-слойного сорбента (7) затрудняет применение этих сорбентов для сорбционного концентрирования при анализе влажного атмосферного или выдыхаемого воздуха с ориентацией на последующую термодесорбцию аналитов. Хотя при этом остается возможность десорбции с помощью подходящего органического растворителя с последующим ВЭЖХ-определением аналитов [30, 31]. В этом случае для десорбции целесообразно использовать тот же органический растворитель, который входит в состав подвижной жидкой фазы, например, ацетонитрил или метанол.

Полученные поверхностно-слойные наноуглеродно-кремнеземные сорбенты и, прежде всего, УНТ-АСГ-900 позволяют проводить экспрессное концентрирование средних спиртов и фенолов из потока влажного воздуха при его высоких скоростях пропускания через 


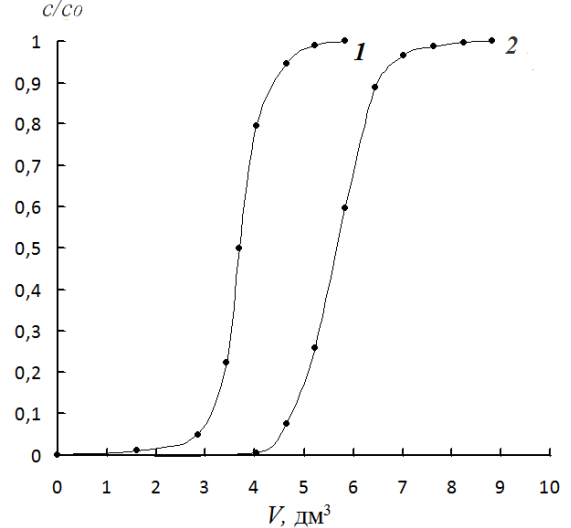

Рис. 1. Выходные кривые удерживания бутанола-1 из потока воздуха $\left(200 \mathrm{~cm}^{3} /\right.$ мин $)$ в колонках $(20 \times 2.5) \mathrm{мм}$, заполненных Карбопаком $X(1)$ и УНТ-

АСГ-900 (2) с размерами частиц (0.18-0.25) MM

Fig. 1. Elution curves of 1-butanol retention from an air flow $\left(200 \mathrm{~cm}^{3} / \mathrm{min}\right)$ in columns $(20 \times 2.5) \mathrm{mm}$ filled with Carbopack $X(1)$ and CNT-ASG-900 (2) with particle sizes $(0.18-0.25) \mathrm{mm}$

колонку с сорбентом, обеспечивая коэффициент концентрирования аналитов $10^{4}$ за 8-10 минут. Выходные кривые удерживания бутанола-1 в сорбционных колонках, заполненных равными навесками (50 мг) Карбопака $X$ и УНТ-АСГ-900 приведены на рис.1. Аналогичные результаты были получены и для фенола (см. рис. 2).

Особенно сильно достоинства поверхностно-слойных сорбентов начинают

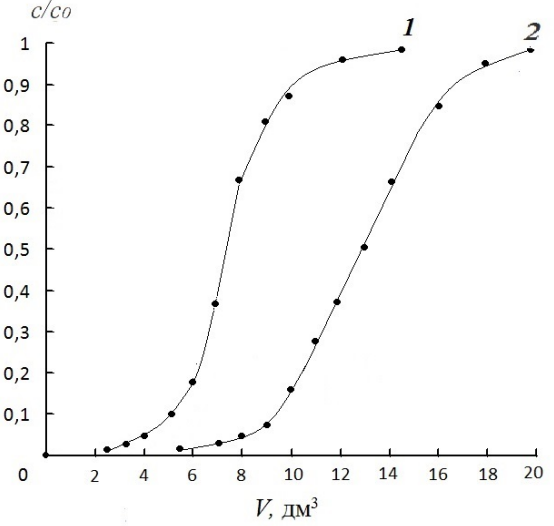

Рис. 2. Выходные кривые удерживания фенола из потока воздуха $\left(200 \mathrm{~cm}^{3} /\right.$ мин $)$ в колонках $(12 \times 2.0) \mathrm{мм}$, заполненных Карбопаком $X(1)$ и УНТ-

АСГ-900 (2) с размерами частиц (0.18-0.25) мм.

Fig. 2. Elution curves of phenol retention from an air flow $\left(200 \mathrm{~cm}^{3} / \mathrm{min}\right)$ in columns $(12 \times 2.0) \mathrm{mm}$ filled with Carbopack $X(1)$ and CNT-ASG-900 (2) with particle sizes $(0.18-0.25) \mathrm{mm}$.

проявляться при высоких скоростях анализируемого воздуха. Это иллюстрирует рис. 3, на котором приведены зависимости ВЭТТ от объемной скорости потока воздуха через сорбционные колонки тех же размеров.

Общеизвестны трудности термодесорбции фенольных соединений с поверхности углеродных адсорбентов. Для

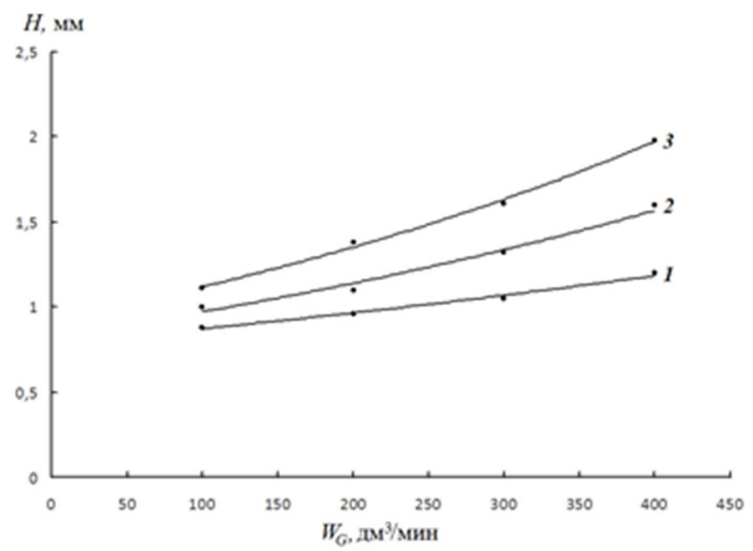

Рис. 3. Зависимость ВЭТТ фенола от объемной скорости потока газовой фазы через колонки $(20 \times 2.5)$ мм, заполненные сорбентами: УНТ-АСГ-900 (1), Карбопак $X(2)$ и УНТ-КСК-2 (3) с размерами частиц (0.18-0.25) мм.

Fig. 3. Dependence of HETP of phenol on the volumetric flow rate of the gas phase through columns $(20 \times 2.5) \mathrm{mm}$ filled with sorbents: UNT-ASG-900 (1), Carbopack $X(2)$ and CNT-KSK-2 (3) with particle sizes $(0.18-0.25) \mathrm{mm}$. 
решения этой проблемы были синтезированы поверхностно-слойные сорбенты со слоем пироуглерода на поверхности макропористого носителя порохром-3 для газовой хроматографии с небольшой удельной поверхностью (см. табл. 1). Полученные сорбенты позволяют проводить сорбционное концентрирование фенола и изо-

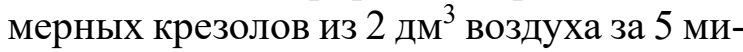
нут в сорбционной колонке $(100 \times 2.5) \mathrm{Mм}$, обеспечивая коэффициент концентрирования $2 \cdot 10^{3}$. Последующая термодесорбция аналитов при $250^{\circ} \mathrm{C}$ обеспечивает их газохроматографическое определение с пламенно-ионизационным детектором, начиная с нескольких мкг/ $\mathrm{M}^{3}$.

\section{Заключение}

Сопоставлены возможности различных сорбентов на основе сорбционно-активных углеродных материалов (графитированной термической сажи, углеродных нанотрубок и пироуглерода) применительно к экспрессному концентрированию летучих органических соединений (средние спирты и фенолы) из потока воздуха. Наибольшая эффективность установлена для поверхностно-слойных сорбентов, полученных путем нанесения на поверхность аэросилогеля углеродных нанотрубок с использованием кобальта в качестве катализатора. Эффективность полученных сорбентов по величине ВЭТТ существенно выше, чем у сорбентов на основе графитированной термической сажи (Карбопаки) с сопоставимой удельной поверхностью. Специально для концентрирования фенольных соединений предложены сорбенты на основе диатомитового носителя (порохром-3), модифицированного пироуглеродом, позволяющие проводить термодесорбцию аналитов. Предложенные сорбенты дают возможность проводить сорбционное концентрирование фенола и изомерных крезолов за 5 минут с коэффициентом концентрирования $2 \cdot 10^{3}$ с последующим газохроматографическим определением аналитов (пламенно-ионизацонный де-

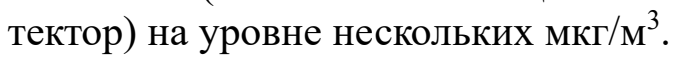

\section{Работа выполнена при поддержке РФФИ (грант № 20-03-00285a) с использованием оборудования Ресурсных центров Научного парка СПбГУ «Методы анализа состава вещества» $u$ «Инновачионные технологии композитных наноматериалов»}

\section{Список литературы}

1. Другов Ю.С., Конопелько Л.А., Попов О.Г. Контроль загрязнений воздуха жилых помещений, офисов, административных и общественных зданий. СПб. Наука. 2013.302 с.

2. Родинков О.В., Спиваковский В., Москвин Л.Н. // Сорбиионные и хроматографические проиессы. 2020. Т. 20. № 2. С. 197-206.

3. Poole C., Mester Z., Miró M., PedersenBjergaard S. et al. // Pur. Appl. Chem. 2016. Vol. 88. No 7. pp. 649-687.

4. Woolfenden E. // J. Chromatogr. A. 2010. Vol. 1217. pp. 2674-2694.

5. Piri-Moghadam H., Ahmadi F., Pawliszyn J. // Trend. Anal. Chem. 2016. Vol. 85.pp. 133-143.

6. Родинков О.В., Журавлёва Г.А. // Аналитика. 2019. Т. 9. № 1. C. 48-58. DOI: 10.22184/2227-572X.2019.09.1.48.58
7. Andrade-Eiroa A., Canle M., Leroy-Cancellieri V., Cerdà V. // Trends Anal. Chem. 2016. Vol. 80. pp. 641-654. DOI: 10.1016/j.trac. 2015.08.015

8. Płotka-Wasylka J., Szczepańska N., Guardia M., Namieśnik J. // Trends Anal. Chem. 2016. Vol. 77. pp. 23-43.

9. Mastrogiacomo A.R., Ottaviani M.F., Pierini E., Cangiotti M. et al. // Chromatographia. 2002. Vol. 55. No 5,6. pp. 345-348.

10. Постнов В.Н., Родинков О.В., Москвин Л.Н., Новиков А.Г. и др. // Успехи химии. 2016. T. 85. № 2. C. 115-138.

11. ГОСТ Р ИСО 16017-1-2007. Воздух атмосферный, рабочей зоны и замкнутых помещений. Отбор проб летучих органических соединений при помощи сорбционной трубки с последующей термодесорбцией и газохроматографическим анализом на капиллярных колонках. М. Стандартинформ, 2008. 32 с. 
12. Березкин В.Г., Никитина Н.С. // Успехи химии. 1971. Т. 40. № 5. С. 927-937.

13. Rodinkov, O.V., Bugaichenko A.S., Vlasov A.Yu. // Talanta. 2014. Vol. 119. pp. 407-411.

14. Родинков О.В., Вагнер Е.А., Бугайченко А.С., Москвин Л.Н. // Журн. аналит. химии. 2019. Т. 74. № 9. С. 673-678.

15. Родинков О.В., Москвин Л.Н. // Журн. аналит. химии. 2012. Т. 67. № 10. С. 908-916.

16. Киселев А.В. Межмолекулярное взаимодействие в адсорбции и хроматографии. М. Высшая школа.1986. 360 с.

17. Киричук О.П., Юрьев Г.О., Буркова Н.В., Постнов В.Н. и др. // Крымский журнал экспериментальной и клинической медицины. 2019. T. 9. №2. C.20-26.

18. Бебрис Н.К., Киселев А.В. Никитин Ю.С. // Коллоидный журнал. 1967. Т. 29. № 3. C. 326-338.

19. Heidaria M., Bahramia A., Ghiasvand A.R., Shahna F.G. et al. // Analuytica Chimica Acta. 2013. Vol. 785. pp. 67-74.

20. Socas-Rodríguez B., Herrera-Herrera A.V., Asensio-Ramos M., Javier Hernández-Borges J.
// Journal of Chromatography. 2014. Vol. 1357. pp. 110-146.

21. Постнов В.Н., Новиков А.Г., Романычев А.И., Мурин И.В. и др. // Журн. общей химии. 2014. T. 84. № 5. C. 870-871.

22. Крохина О.А., Постнов В.Н. // Нанотехника 2010. Т. 22. № 2. С. 39-44.

23. Плаченов Т.Г., Колосенцев С.Д. Порометрия. Л. Химия. 1988. $100 \mathrm{c.}$

24. Платонов И.А., Родинков О.В., Горбачева А.Р., Москвин Л.Н. и др. // Журн. аналит. химии. 2018. Т. 73. № 2. С. 83-101.

25. Витенберг А.Г., Иоффе Б.В. Газовая экстракция в хроматографическом анализе: парофазный анализ и родственные методы. Л. Химия. 1982. С. 23.

26. Немировский А.М. // Завод. лаб. 1996. Т. 62. № 3. C. 13-18.

27. Brown V.M., Crump D.R., Plant N.T., Pengelly I. // J. Chromatogr. A. 2014. Vol. 1350. pp. 1-9. $\quad$ http://dx.doi.org/10.1016/j.chroma. 2014.05.011

28. Медведев Е.И., Родинков О.В. // Сорбиионные и хроматографические прочессы. 2017. T. 17. № 1. C. 110-116.

\title{
Comparison of the capabilities of carbon sorption-active materials for the express concentration of volatile organic compounds from the flow of analysed air
}

\author{
(C) 2021 Rodinkov O.V., Postnov V.N., Spivakovsky V., Bugaychenko A.S. \\ St. Petersburg State University, Institute of Chemistry, St. Petersburg
}

\begin{abstract}
Carbon sorbents are widely used for dynamic sorption concentration of analytes in air analysis. However, carbon and especially nanocarbon sorption-active materials have one significant drawback. Too small particles of these materials often impede their direct use in air analysis due to the low permeability of the sorption layer. The problem of low permeability of microdispersed sorption-active materials can be solved using composite surface-layer sorbents, in which these materials are located on the surface of a relatively coarsely dispersed carrier.

The main goal of this study was assessment of the capabilities of surface-layer sorbents based on various carbon materials for the rapid concentration of highly toxic volatile organic compounds (medium alcohols and phenols). Surface-layer sorbents based on commercially available carbon nanotubes (Bauer, Dealton, Taunit-MD) and nanotubes synthesized by us using a cobalt catalyst have been synthesized and investigated. The listed carbon sorbents were applied to silica supports based on an aerosilogel. The choice of these carriers was due to their high thermal stability and the possibility of depositing layers of pyrocarbon and carbon nanotubes on their surface. In addition, these carriers allow creating composites with a wide variety of sorption-active carbon materials.

The highest efficiency was found for surface-layer sorbents based on carbon nanotubes obtained using a cobalt catalyst. The efficiency of these sorbents in terms of HETP value was significantly higher than that of sorbents based on graphitized thermal soot (Carbopacks) with a comparable specific surface area. The advantages of surface-layer sorbents begin to manifest themselves especially strongly with a high flow rate of the analysed air. The increased hydrophilicity of some synthesized composites complicated their use in the analysis of moist air with an orientation towards the subsequent thermal desorption of analytes. However, this
\end{abstract}


leaves the possibility of desorption using a suitable organic solvent, followed by determination of analytes by HPLC.

The difficulties of thermal desorption of high-boiling organic compounds from the surface of carbon adsorbents are well known. For the solution of this problem, surface-layer sorbents with a pyrocarbon layer on the surface of the porochrome-3 macroporous carrier for gas chromatography with a small specific surface were synthesized. The proposed sorbents allowed performing the sorption concentration of phenol and isomeric cresols in $5 \mathrm{~min}$ with a concentration factor of $2 \cdot 10^{3}$ followed by gas chromatographic determination of analytes (flame ionization detector) at a level of several $\mu \mathrm{g} / \mathrm{m}^{3}$. This creates the necessary prerequisites for the rapid determination of phenol and isomeric cresols at the level of maximum permissible air concentrations in residential premises and atmospheric air in populated areas.

Keywords: sorbents, surface-layer, concentration, air, analysis, carbon nanotubes, aerosilogel, phenols, alcohols.

\section{References}

1. Drugov Yu.S., Konopel'ko L.A., Popov O.G. Kontrol' zagrjaznenij vozduha zhilyh pomeshenij, ofisov, administrativnyh i obshhestvennyh zdanij. SPb., Nauka, 2013, 302 p.

2. Rodinkov O.V., Spivakovskij V., Moskvin L.N., Sorbtsionnye i khromatograficheskie protsessy, 2020, Vol. 20, No 2, pp. 197-206.

3. Poole C., Mester Z., Miró M., PedersenBjergaard S., et al., Pur. Appl. Chem., 2016, Vol. 88 , No 7, pp. 517-558. DOI: $10.1515 /$ pac-20150903

4. Woolfenden E., J. Chromatogr. A, 2010, Vol. 1217, pp. 2685-2694. DOI: 10.1016/j.chroma.2 010.01.015

5. Piri-Moghadam H., Ahmadi F., Pawliszyn J., Trend. Anal. Chem., 2016, Vol. 85, pp. 133143. DOI: 10.1016/j.trac.2016.05.029

6. Rodinkov O.V., Zhuravljova G.A., Analitika, 2019, Vol. 9, No 1, pp. 48-58. DOI: 10.22184/2227-572X.2019.09.1.48.58

7. Andrade-Eiroa A., Canle M., LeroyCancellieri V., Cerdà V., Trends Anal. Chem., 2016, Vol. 80, pp. 641-654. DOI: 10.1016/j.trac.2015.08.015

8. Płotka-Wasylka J., Szczepańska N., de la Guardia M., Namieśnik J., Trends Anal. Chem., 2016, Vol. 77, pp. 23-43. DOI: 10.1016/j.trac.2015.10.010

9. Mastrogiacomo A.R., Ottaviani M.F., Pierini E., Cangiotti M. et al., Chromatographia, 2002, Vol, 55. No 5, 6, pp. 345-348 DOI: 10.1007/BF02491670

10. Postnov V.N., Rodinkov O.V., Moskvin L.N., Novikov A.G. et al., Uspehi himii, 2016, Vol. 85, No 2, pp. 115-138. DOI: 10.1070/RCR4551
11. GOST R ISO 16017-1-2007. Vozduh atmosfernyj, rabochej zony i zamknutyh pomeshhenij. Otbor prob letuchih organicheskih soedinenij pri pomoshhi sorbcionnoj trubki $\mathrm{s}$ posledujushhej termodesorbciej i gazohromatograficheskim analizom na kapilljarnyh kolonkah. M., Standartinform, 2008, 32 p.

12. Berezkin V.G., Nikitina N.S., Uspehi himii, 1971, Vol. 40, No 5, pp. 927-937.

13. Rodinkov O.V., Bugaichenko A.S., Vlasov A.Yu., Talanta, 2014, Vol. 119, pp. 407411. DOI: $10.1016 /$ j.talanta.2013.11.040

14. Rodinkov O.V., Vagner E.A., Bugajchenko A.S., Moskvin L.N., J. Analyt. Chem., 2019, Vol. 74, No 9, pp. 877-882. DOI: 10.1134/S1061934819090089

15. Rodinkov O.V., Moskvin L.N. //J. Analyt. Chem, 2012, Vol. 67, No 10, pp. 814-822. DOI: $10.1134 / \mathrm{S} 1061934812100073$

16. Kiselev A.V. Mezhmolekuljarnoe vzaimodejstvie v adsorbcii i hromatografii, M., Vysshaja shkola, 1986, $360 \mathrm{p}$.

17. 17. Kirichuk O.P., Jur'ev G.O., Burkova N.V., Postnov V.N. et al., Krymskij zhurnal jeksperimental'noj i klinicheskoj mediciny, 2019, Vol. 9, No 2, pp. 20-26.

18. Bebris N.K., Kiselev A.V. Nikitin Ju.S., Kolloidnyj zhurnal, 1967, Vol. 29, No 3, pp. 326-338.

19. Heidaria M., Bahramia A., Ghiasvand A.R., Shahna F.G. et al., Analuytica Chimica Acta, 2013, Vol. 785, pp. 67-74. https://doi.org/10.1016/j.aca.2013.04.057

20. Socas-Rodríguez B., Herrera-Herrera A.V., Asensio-Ramos M., Javier HernándezBorges J., Journal of Chromatography, 2014, 
Vol. 1357, pp. 110-146. http://dx.doi.org/ 10.1016/j.chroma.2014.05.035

21. Postnov V.N., Novikov A.G., Romannychev A.I., Murin I.V. et al., Russ. J. Gen. Chem., 2014, Vol. 84, No 5, pp. 962-963. DOI: $10.1134 / \mathrm{S} 1070363214050302$

22. Krohina O.A., Postnov V.N., Nanotehnika, 2010, Vol. 22, No 2, pp. 39-44.

23. Plachenov T.G., Kolosencev S.D. Porometrija. L., Himija, 1988, P. 100.

24. Platonov I.A., Rodinkov O.V., Gorbacheva A.R., Moskvin L.N. et al., J. Analyt. Chem., 2018, Vol. 73, No 2, pp. 109-127. DOI: $10.1134 /$ S1061934818020090

Родинков Олег Васильевич - профессор кафедры аналитической химии, д.х.н., СанктПетербургский государственный университет, Институт химии Санкт-Петербург

Постнов Виктор Николаевич - доцент кафедры химии твердого тела, к.х.н., Санкт-Петербургский государственный университет, Институт химии Санкт-Петербург

Спиваковский Валерий - стажер-исследователь, Санкт-Петербургский государственный университет, Институт химии Санкт-Петербург

Бугайченко Александра Сергеевна - старший преподаватель кафедры аналитической химии, к.х.н., Санкт-Петербургский государственный университет, Институт химии Санкт-Петербург
25. Vitenberg A.G., Ioffe B.V. Gazovaja jekstrakcija $\mathrm{V}$ hromatograficheskom analize: parofaznyj analiz i rodstvennye metody, L., Himija, 1982, p. 23.

26. Nemirovskiy A.M., Zavod. lab., 1996, Vol. 62, No 3, pp. 13-18.

27. Brown V.M., Crump D.R., Plant N.T., Pengelly I., J. Chromatogr. A, 2014, Vol. 1350, pp. 1-9. http://dx.doi.org/10.1016/j.chroma. 2014.05.011

28. Medvedev E.I., Rodinkov O.V., Sorbtsionnye i khromatograficheskie protsessy, 2017, Vol. 17, No 1, pp. 110-116.

Rodinkov Oleg V. - Professor, Department of Analytical Chemistry, Doctor of Chemical Sciences, St. Petersburg State University, Institute of Chemistry, St. Petersburg

Postnov Viktor N. - Associate Professor of the Department of Solid State Chemistry, Candidate of Chemical Sciences, St. Petersburg State University, Institute of Chemistry, St. Petersburg

Spivakovsky Valery - Research Assistant, St. Petersburg State University, Institute of Chemistry, St. Petersburg

Bugaychenko Alexandra S. - Senior Lecturer, Department of Analytical Chemistry, Ph.D., St. Petersburg State University, Institute of Chemistry, St. Petersburg 